\title{
Step changes in persistent organic pollutants over the Arctic and their implications
}

\author{
Y. Zhao, T. Huang, L. Wang, H. Gao, and J. Ma
}

Key Laboratory for Environmental Pollution Prediction and Control, Gansu Province, College of Earth and Environment Sciences, Lanzhou University, Lanzhou 730000, China

Correspondence to: J. Ma (jianminma@1zu.edu.cn)

Received: 13 October 2014 - Published in Atmos. Chem. Phys. Discuss.: 15 January 2015

Revised: 16 March 2015 - Accepted: 17 March 2015 - Published: 31 March 2015

\begin{abstract}
While some persistent organic pollutants (POPs) have been declining globally due to their worldwide ban since the 1980s, the declining trends of many of these toxic chemicals become less significant and in some cases their ambient air concentrations, e.g., polychlorinated biphenyls (PCBs), showed observable increase during the 2000s, disagreeing with their declining global emissions and environmental degradation. As part of the efforts to assess the influences of environmental factors on the long-term trend of POPs in the Arctic, step change points in the time series of ambient POP atmospheric concentrations collected from four arctic monitoring sites were examined using various statistical techniques. Results showed that the step change points of these POP data varied in different years and at different sites. Most step change points were found in 2001-2002 and 20072008. In particular, the step change points of many PCBs for 2007-2008 were coincident with the lowest arctic sea ice concentration occurring during the 2000s. The perturbations of air concentration and water-air exchange fluxes of several selected POPs averaged over the Arctic, simulated by a POP mass balance perturbation model, switched from negative to positive during the early 2000 s, indicating a tendency for reversal of POPs from deposition to volatilization which coincides with a positive to negative reversal of arctic sea ice extent anomalies from 2001. Perturbed ice-air exchange flux of PCB 28 and 153 showed an increasing trend and a negative to positive reversal in 2007 , the year with the lowest arctic sea ice concentration. On the other hand, perturbed ice-air exchange flux of $\alpha$-hexachlorocyclohexane decreased over the period of 1995 to 2012, likely owing to its lower Henry's law constant which indicates its relatively lower tendency for volatilization from ice to air.
\end{abstract}

\section{Introduction}

A number of studies have been carried out to examine temporal trends of persistent organic pollutants (POPs) in the Arctic (Hung et al., 2005, 2010; Becker et al., 2008; Ma et al., 2011; Wöhrnschimmel et al., 2013). Due to worldwide ban and restrictions of these toxic chemicals, most legacy POPs have been declining in the Arctic over the last several decades. Fluctuations of many POPs on interannual or longer timescales, however, have been observed in POP time series collected from arctic monitoring stations. The longterm trends of POPs in the Arctic have been attributed to the changes in their primary emissions, use patterns, retreating sea ice, degradation, and other complex natural and anthropogenic activities (Macdonald et al., 2005; UNEP/AMAP, 2010; Armitage et al., 2011; Kallenborn et al., 2012). The fluctuations of monitored POP atmospheric concentrations have been also associated with interannual climate change at several POP monitoring sites where the longest atmospheric monitoring programs have been operated, notably the Great Lakes region and the Arctic (Ma et al., 2004a; MacLeod et al., 2005; Wang et al., 2010). The notable interannual climate change influencing interannual changes in elevated atmospheric level of POPs in the Northern Hemisphere are the North Atlantic Oscillation (NAO), the El Niño-Southern Oscillation (ENSO), and the Arctic Oscillation (Ma et al., 2004a, b; Ma and Li, 2006; MacLeod et al., 2005; Macdonald, 2005; Becker et al., 2008; Gao et al., 2010). These studies have revealed abundant evidence for the associations between the interannual climate change and ambient atmospheric concentrations of POPs in the Great Lake and arctic regions. 
Previous trend assessments for POP concentration time series in the Arctic have revealed changes in these time series induced potentially by climate change. The relationship between ambient POP air concentrations and rapid change in the arctic environment has, however, not been proven statistically. Recently, there has been ongoing debate on a climate "tipping point" (Lenton, 2011; Duarte et al., 2012; Livina and Lenton, 2013; Holland et al., 2006) in the Arctic. The tipping point has been connected to an abrupt increase in the amplitude of seasonal variability of sea ice area in 2007 that has been persistent since then, indicating the likelihood of rapid arctic climate change (Livina and Lenton, 2013). It is worthwhile to point out that arctic climate change occurs on a much longer timescale than the lifetime of POPs and it might not be appropriate to link short-term changes in POP environmental level with long-term climate change. However, the rapid change in arctic environments would change the environmental fate and temporal trend of POPs, together with their primary emissions and use patterns in the globe. Yet, the response of the monitored POP long-term time series in the Arctic to the rapid change in the arctic environment has not been investigated intensively. POPs releasing from seasonal melting snow pack and mountain glaciers has been demonstrated to alter significantly the atmospheric levels of POPs (Stocker et al., 2007; Bogdal et al., 2009; Meyer and Wania, 2008). Except for permanent ice and glaciers, Arctic sea ice as a temporal storage reservoir for POPs undergoes seasonal changes. The sea ice melting and aging may increase air concentrations of POPs. It was observed that an abrupt increase in $\alpha$-hexachlorocyclohexane $(\alpha-\mathrm{HCH})$ concentrations in the air occurred in tandem with the ice breakup in the central Archipelago during the Tundra Northwest 1999 (TNW99) expedition (Jantunen et al., 2007). Increasing concentrations of hexachlorobenzene (HCB) and many polychlorinated biphenyl (PCB) congeners were also observed in arctic air from the mid-2000s at the Zeppelin Mountain Air Monitoring Station, Svalbard/Norway $\left(78^{\circ} 55^{\prime} \mathrm{N}, 11^{\circ} 56^{\prime} \mathrm{E}\right)$, and the Alert station, Canada $\left(82^{\circ} 30^{\prime} \mathrm{N}, 62^{\circ} 19^{\prime} \mathrm{W}\right)$, resulting in the lack of statistically significant trends of these chemicals in the Arctic since the late 1990s (Hung et al., 2010). While the increasing trends of HCB and PCBs in the 2000s in the Arctic have been attributed partly to their revolatilization from their arctic repertories in ocean, ice, and snow due to arctic warming and sea ice retreat (Hung et al., 2010; Ma et al., 2011; Becker et al., 2012), this hypothesis was not supported sufficiently by statistical evidence.

To identify decadal or longer timescale climate change (e.g., global warming) signals, a time series of climate data should not be shorter than 30 years (the classical climate change period; Le Treut et al., 2007). This raises the question of whether currently available POP observational data sets are long enough to address climate change influence on their environmental fate. Several recent modeling investigations and sensitivity analysis to the long-term trend of PCBs and $\alpha$ $\mathrm{HCH}$ in the 20th and 21st centuries suggested that the long- term trends of these POPs were associated more strongly with changes in their emissions and physical-chemical properties, whereas climate change signals were weaker in observed POP time series (Wöhrnschimmel et al., 2013; Armitage et al., 2011; Gouin et al., 2013; Li, 2012).

Since the Arctic is warming at a rate of almost twice the global average, which leads to strong sea ice melt since the 2000s (Steele et al., 2008), the measured POP atmospheric concentrations in the Arctic might provide the best data sets to discern the signals of climate change in monitored POP data. The increasing trend of PCBs appeared to coincide to the strong sea ice melt in the Arctic, characterized by rapid decline in arctic sea ice from 2000 (Duarte et al., 2012). Since the sea ice decline took place over a short period of time, the monitored POP air concentrations data sets in the Arctic, though short, would likely respond to rapid sea ice decline and increasing air temperature, which may provide further field evidence to the association between temporal trend of POPs and climate warming. The present study examined the statistics for step changes in monitored atmospheric concentrations of POPs at several arctic monitoring stations. The association between the statistically significant step change points of POP concentrations and arctic climate change was quantitatively assessed to identify arctic climate change signals in measured POP time series.

\section{Materials and methods}

\subsection{Data}

Monitored ambient atmospheric concentrations of selected PCBs and OCPs (organochlorine pesticides) in the present study were collected from four Arctic monitoring sites representing the longest time series of POPs across the Arctic. These are the Zeppelin Mountain air-monitoring station (Svalbard/Norway, 1992-2012), Alert (Canada, 1993-2012), Pallas (Matorova, Finland; $68^{\circ} 00^{\prime} \mathrm{N}, 2^{\circ} 15^{\prime} \mathrm{E}$; 1996-2011), and Storhofdi (Vestmannaeyjar, Iceland; $63^{\circ} 24^{\prime} \mathrm{N}, 20^{\circ} 17^{\prime} \mathrm{W}$; 1995-2011). The sampling frequencies vary site by site. At Zeppelin, Alert, and Pallas sites, daily air concentrations are sampled every week, and at Storhofdi site the daily concentrations are sampled every 2 weeks. Detailed information about sample collection and chemical analysis are found in Hung et al. (2010). The annual mean air concentrations at each site were obtained by averaging weekly (Zeppelin, Alert, Pallas) or bi-weekly (Storhofdi) sampled data. The concentrations of selected POPs in the Arctic oceans and ice (snow) used in subsequent perturbation modeling were collected from literature and listed in Table S1 in the Supplement. These data were not routinely measured. Since the perturbation model (see Sect. 2.3) only inputs multiple yearly averaged concentration data in air, water, and ice/snow as forcing terms to predict perturbed concentrations ( $\mathrm{Ma}$ and Cao, 2010) and set initial concentration perturbations as zero, 
POP concentration data in the Arctic oceans and sea ice/snow collected from different years and locations were averaged over the Arctic and entire monitoring period from the 1990s to 2012. Monthly averaged arctic sea ice extent and area data were collected from the National Snow and Ice Data Center (NSIDC at http://nsidc.org; Clark, et al., 1999). Surface air temperature and precipitation data used in perturbation modeling were collected from the National Centers for Environmental Prediction (NCEP) reanalysis (Kalney et al., 1996). Physical-chemical properties of selected POPs in perturbation modeling are presented Table S2 in the Supplement.

\subsection{Statistical test for POP trends and step change}

Searching for a step change (also referred to abrupt change or abrupt discontinuities) in a time series is often conducted by the detection of a point year as a sign of step change in the time series. It is the process of finding step changes (or shifts) in the mean level of the time series. In the cases of POP atmospheric concentration time series, the step changes can be considered as a statistically significant abnormal increasing or decreasing from their long-term trend, extending to a certain period of time. In climate and hydrological studies, three statistical methods have been widely used to identify abrupt climate change points. These are the Mann-Kendall (MK) test (Mann, 1945; Kendall, 1955), the moving $t$ test (MTT) technique (Moraes, et al., 1998), and the Yamamoto method (Yamamoto et al., 1985).

The MK test is a nonparametric statistical test (Kendall, 1955) which has been used to find trend and step change points of hydrological stream flows and air temperatures (Moraes et al., 1998; Gan, 1998). Under the null hypothesis (no step change point), the normally distributed statistic $S_{k}$ can be calculated as

$S_{k}=\sum_{i=1}^{k} r_{i} \quad(k=2,3, \ldots, n)$,

where $S_{k}$ is a statistic of the MK test, and

$r_{i}=\left\{\frac{+1,\left(x_{i}>x_{j}\right)}{0,\left(x_{i} \leq x_{j}\right)}\right\} \quad(j=1,2, \ldots, i-1)$,

where $x_{i}$ is $i$ th variable in time series $x_{1}$ and $x_{2}, \ldots, x_{i}, r_{i}$ is the cumulative number for $x_{i}>x_{j}$. The expected values $E\left(S_{i}\right)$ and variance $\operatorname{Var}\left(S_{i}\right)$ of $S_{k}$ are given by

$E\left(S_{i}\right)=\frac{i(i-1)}{4}$,

$\operatorname{Var}\left(S_{i}\right)=\frac{i(i-1)(2 i+5)}{72}$.

From these two equations one can derive a normalized $S_{i}$, defined by

$U F_{i}=\frac{S_{i}-E\left(S_{i}\right)}{\sqrt{\operatorname{Var}\left(S_{i}\right)}} \quad(i=1,2, \ldots, n)$, where the normalized variable statistic $U F_{i}$ is the forward sequence. Likewise, the backward sequence $U B_{i}$ can be calculated using the same equation but taking a reversed series of the data such that $U B_{i}=-U F_{i}$. When the null hypothesis is rejected (i.e., if any of the points in the forward sequence are outside the confidence interval), the detection of an increasing $\left(U F_{i}\right)$ or a decreasing $\left(U B_{i}\right)$ trend is determined. In this way the sequential version of the test enables detection of an approximate time of occurrence of the trend by locating the intersection of the forward and backward curves of the test. The intersection occurring within the confidence interval indicates the beginning of a step change point (Moraes et al., 1998; Zhang et al., 2011).

The idea of the moving $t$ test technique is to test the difference between two subsamples of a random variable time series before and after the change point with equivalent subsample sizes under a null hypothesis of $u 1=u 2$, where $u 1$ and $u 2$ are two subsamples. In other words, if the difference between means over two adjacent time intervals reaches a statistical significance level, a step change is inferred to occur. For a time series whose population is normally distributed, the $t$ statistics is defined as (Moraes et al., 1998)

$$
\begin{aligned}
t_{0} & =\frac{\overline{x_{1}}-\overline{x_{2}}}{S_{p}\left(\frac{1}{n_{1}}+\frac{1}{n_{2}}\right)^{\frac{1}{2}}}, \\
S_{p}^{2} & =\frac{\left(n_{1}-1\right) S_{1}^{2}+\left(n_{2}-1\right) S_{2}^{2}}{n_{1}+n_{2}-2},
\end{aligned}
$$

where $S_{i}^{2}$ and $n_{i}$ are variance and sample size, respectively. In the present study, we requested that when $t$ statistics $t_{0}$ at a point year beyond the control line at $t_{0}= \pm 0.46$ reaches the significant level $\alpha=0.01$, this point year will be identified as a step change point year.

The Yamamoto method is somewhat similar to the MTT approach, defined by a signal-to-noise ratio $(S / N$, Yamamoto et al., 1985):

$$
\frac{S}{N}=\frac{\left|\overline{x_{1}}-\overline{x_{2}}\right|}{S_{1}+S_{2}} .
$$

A step point of a concentration time series is inferred when $S / N$ intersects with the line of $S / N=2.66$ at the significant level $\alpha=0.01$. In the present study, the subset data size of both Yamamoto and MTT methods was set to 3. Table S3 in the Supplement compares the MTT method identified step change point years for PCBs for the period of 2007-2012 at the Zeppelin site using the subsample size $\mathrm{IH}=3$ and 4 . For most PCBs, the selection of the subsample size $\mathrm{IH}=3$ yielded the step change year 2008, while choosing the subsample size $\mathrm{IH}=4$ yielded the year 2007. It should be noted that, since the subset size $u 1=u 2$ requires the even number of data points, the data points in POP time series used in the step change statistical test by these two methods were less than the number of measured data. 
Since the changes in atmospheric concentrations of POPs are often driven by the first-order processes that scale multiplicatively with the concentrations (Meijer et al., 2003), all concentrations in the MTT and Yamamoto statistics are logtransformed (in natural logarithm) before they are used in the statistical analysis. Because the MK method is a rank-based test, the log-transformed time series make no difference from original time series for the step change results.

These methods each have their advantages and disadvantages. For example, while the MK test has been successfully used in detecting step change points (Moraes et al., 1998; Gan, 1998), it failed to discern statistically significant signals in step changes in some cases. To increase confidence of the statistical test for potential step change point in the selected POP time series, the present study applied simultaneously the MK test, MTT technique, and Yamamoto method. Although the step change points of a time series from the MK test may occur in a certain year, this year is often regarded as the onset year of the step change. The year immediate after the onset year can be also included in the period of the step change in the time series. We also applied monthly and seasonal mean air concentrations data at the four arctic sites to examine the step change points for monitored POP concentrations. The monthly and seasonal mean concentrations were compiled by averaging weekly (Zeppelin, Alert, Pallas) or bi-weekly (Storhofdi) sampled air concentrations. Using monthly or seasonally averaged time series can increase sample size. However, periodic variations in monthly and seasonal POP concentration time series, characterized by higher concentrations in warmer months (or season) and lower concentrations in colder months (or season), overwhelmed the changes in annually averaged concentration time series. Our results showed that the monthly and seasonal averaged data could not yield step changes for most POP data. Figure S1 in the Supplement displays the $U F_{i}$ and $U B_{i}$ in the MK test (Eq. 5) for monthly PCB 28 atmospheric concentration time series during the summer months in the Arctic at Zeppelin site. As seen, $U F_{i}$ and $U B_{i}$ fluctuate below the confidence level, and no statistically significant step changes are found. Further details in the influence of sample size, monthly and seasonal time series on step changes in POP air concentrations are presented in the Supplement.

\subsection{Perturbation modeling}

The coupled air-surface perturbation model for POPs was developed by Ma and Cao (2010) and Ma et al. (2011) to simulate and predict perturbations of POP concentrations in various environmental media under projected climate change scenarios. This approach defined the concentration $\left(C, \mathrm{pg} \mathrm{m}^{-3}\right)$ of a persistent chemical (and other variables) in an environmental compartment (e.g., air, water, snow, ice, sediment) to equal the sum of its mean concentration $(\bar{C})$ and perturbed concentrations $\left(C^{\prime}\right): C=\bar{C}+C^{\prime}$ or $C^{\prime}=C-\bar{C}$. So $C^{\prime}$ can also be regarded as a concen- tration anomaly (or departure) from its mean. The change in this mean concentration in the Arctic was often dominated by its primary emission, degradation, and disequilibrium or exchange of concentrations between two environmental compartments (Gioia et al., 2008). These processes control the mean state of POPs in environment, whereas the perturbed concentration $C^{\prime}$, as the departure from these mean processes, might be more sensitive to other processes with weak signals in ambient POP concentrations, such as climate change. The model was developed to quantify the response of POPs in multi-environmental compartments to the long-term changes in atmospheric and ocean temperatures and snow and sea ice. In the case of the arctic environment, the model simulates daily concentrations of POPs (with the model time step length at 1 day) in different environmental compartments forced mostly by the change in temperatures, ice/snow melting, and the mean concentrations (Table S1 in the Supplement). The model can be applied either in a single spatial site or entire arctic region. Details in the perturbation model were referred to Ma and Cao (2010) and Ma et al. (2011). To interpret the occurrence of step change point years of POP concentration data detected by the statistical analysis, the perturbation modeling for PCB 28,153 , and $\alpha$ $\mathrm{HCH}$ was performed using their mean and perturbed emissions. To examine the response of the exchange of POPs in multi-media environments to their step changes, perturbed water-air and ice-air exchange flux were also calculated. It is arguable that the most processes that control the concentration in air are first-order processes that scale multiplicatively with concentrations, whereas the perturbation model treats concentrations in air as a linear sum of their mean and perturbed concentrations (Ma and Cao, 2010). It must be noted, as aforementioned, that the sole external forcing term in the perturbation model was the mean concentration in different environmental compartments and initial perturbed concentrations were set zero in the model (Ma and Cao, 2010). Those nonlinear processes related to the chemical-physical properties of a chemical and their associations with temperature have been also taken into consideration through the calculation of their mean and perturbation.

The global emission inventory of selected POPs employed in the perturbation modeling $\alpha-\mathrm{HCH}$ and PCBs used the results from $\mathrm{Li}$ et al. (2000) and Breivik et al. (2007). We implemented mean and perturbed air emissions, subjected to mean temperatures and temperature anomalies, into the model, expressed as (Lamon et al., 2009; Ma and Cao, 2010; Gouin et al., 2013)

$$
\begin{aligned}
& \bar{E}_{\mathrm{OHC}}=E_{\mathrm{OHC}-\operatorname{ref}} \exp \left[\Delta U_{A} \frac{\left(\frac{1}{T_{\mathrm{ref}}}-\frac{1}{\bar{T}}\right)}{R}\right], \\
& E_{\mathrm{OHC}}^{\prime}=\frac{\Delta U_{A}}{R} \bar{E}_{\mathrm{OHC}} \frac{T^{\prime}}{\bar{T}^{2}},
\end{aligned}
$$


where $T_{\text {ref }}$ is the reference temperature $(\mathrm{K})$ and $E_{\mathrm{OHC}-\text { ref }}$ is the emission at the reference temperature, obtained from an emission inventory. $\Delta U_{A}$ is the internal energy of vaporization (Lamon et al., 2009). Since $\bar{E}_{\mathrm{OHC}}$ does not change with temperature and time, it can be linked with the mean air concentration in our model.

The instantaneous water-air exchange flux is calculated by the Whitman two-film model (Bidleman and McConnell, 1995):

$F_{\mathrm{w}}=K_{\mathrm{OL}}\left(C_{\mathrm{w}}-C_{\mathrm{a}} R T / H\right)$,

where $F_{\mathrm{w}}$ is the water-air exchange flux, $K_{\mathrm{OL}}$ is the airwater exchange velocity, $C_{\mathrm{w}}$ is dissolved concentration in water, $C_{\mathrm{a}}$ is air concentration, $H$ is the Henry's law constant, and $R$ is the ideal gas constant. Equation (11) suggests that, at the interface between water and air, POP concentration in air and water is in equilibrium through the Henry's law constant, defined as $C_{\mathrm{a}} / C_{\mathrm{w}}=H / R T$. Following the rules in perturbation theory (Ma and Cao, 2010) one can derive the perturbed water-air exchange flux as

$$
\begin{aligned}
F^{\prime} & =\bar{K}_{\mathrm{OL}}\left[\frac{R}{\bar{H}}\left(\frac{\bar{T} C_{\mathrm{a}}}{\overline{\bar{H}}} H^{\prime}-\bar{T} C_{\mathrm{a}}^{\prime}-\bar{C}_{\mathrm{a}} T^{\prime}\right)+C_{\mathrm{w}}^{\prime}\right] \\
& +K_{\mathrm{OL}}^{\prime}\left(\bar{C}_{\mathrm{w}}-\frac{R \bar{T}}{\bar{H}} \bar{C}_{\mathrm{a}}\right) .
\end{aligned}
$$

Calculations of mean and perturbed $K_{\mathrm{OL}}$ and $H$ followed Ma and Cao (2010). Likewise, the ice-air exchange flux can be defined, assuming that the ice-air exchange process is the same as the snow-air exchange, as

$$
F_{i}=v_{\mathrm{a}}\left(\frac{C_{\mathrm{i}}}{K_{\mathrm{sa}}}-C_{\mathrm{a}}\right),
$$

where $C_{\mathrm{i}}$ is the concentration in ice, $v_{\mathrm{a}}$ is the exchange velocity of a chemical between air and ice $\left(\mathrm{m} \mathrm{s}^{-1}\right)$, and $K_{\text {sa }}$ is the ice-air partition coefficient. The expressions of these mean and perturbed parameters were obtained from Ma et al. (2011). The perturbed ice-air exchange flux is given by

$$
\begin{aligned}
F_{i} & =\bar{v}_{\mathrm{a}}\left[\frac{1}{K_{\mathrm{sa}}}\left(C_{\mathrm{i}}^{\prime}-\frac{K_{\mathrm{sa}}^{\prime}}{\bar{K}_{\mathrm{sa}}} \bar{C}_{\mathrm{i}}\right)-C_{\mathrm{a}}^{\prime}\right] \\
& +v_{\mathrm{a}}^{\prime}\left(\frac{\bar{C}_{\mathrm{i}}}{\bar{K}_{\mathrm{sa}}}-\bar{C}_{\mathrm{a}}\right) .
\end{aligned}
$$

\section{Results}

\subsection{Step change points by MK test}

The number of PCB congeners and OCPs measured at different sites differs from each other. We have calculated the step change points for all monitored PCBs and OCPs at each monitoring site. The presence of these points in the monitored PCBs and OCPs was not identical but varied with different chemicals at different monitoring sites. It is impossible to illustrate the step change points for all POP time series at all monitoring sites. In the present study, only those chemicals whose forward and backward sequences $\left(U F_{i}\right.$ and $\left.U B_{i}\right)$ lay partly within the confidence interval $(-1.96-1.96)$ in the MK test were selected for step change analysis.

\subsubsection{Alert}

Figure 1 displays $U F_{i}$ and $U B_{i}$ for 16 PCBs and 9 OCPs derived by the MK test (Eq. 5) at Alert monitoring station. As defined, the intersections between the forward and backward sequences $U F_{i}$ (curved blue line) and $U B_{i}$ (curved red line) within the confidence levels of -1.96 (straight purple line) to 1.96 (straight green line) denote step change points for these POP time series. As shown, $U F_{i}$ and $U B_{i}$ intersected at least once over the period of 1993 to 2012. Most intersections were well within the confidence levels between -1.96 and 1.96 at the statistical significance $\alpha=0.01$, except for $\alpha$ - and $\gamma$-HCH whose intersections were outside the confidence level. Hence, there were no step change points of these two $\mathrm{HCH}$ isomers. The two step change points in 1997 and 2004 were detected for $\beta$-HCH. $\beta$-HCH partitions much more strongly into cold water than $\alpha-\mathrm{HCH}$. Ocean currents and river currents were thought to dominate the entry of $\beta$-HCH into the western Arctic Ocean (Li et al., 2002). Elevated concentrations of $\beta-\mathrm{HCH}$ in the air over the Canadian Arctic might be partly explained by its outgassing from the nearby ocean. It is not clear if the two step change years of this $\mathrm{HCH}$ isomer were attributable to its revolatilization following its increasing oceanic transport. The increasing trend of $U F_{i}$ for $\beta$-HCH from 2002 at Alert, suggesting its increasing air concentration, was not observed at other monitoring sites which are farther from the western Arctic Ocean than the Alert site.

For tri-PCBs, three step change points were found between 2000 and 2005 (PCB 16, 25, and 26) and two found in 1998 (PCB 18 and 25). The step change points in PCB 44, 49, 105, 106, and 209 were also found after 2000 but more step change points in tetra-, penta-, hexa-, and deca-PCBs were detected before 2000. On the other hand, the step change points in all six DDT (dichlorodiphenyldichloroethane) isomers were found after 2000 and the four of these six DDT isomers showed step change points before 2000. It can be also observed that, though $U F_{i}$ and $U B_{i}$ were intersected over 2001-2002, the point of the intersection was outside of the confidence level. Hence, this point was not regarded as a step change point. The number of chemicals with statistically significant step change points for different periods is presented in Table 1. 

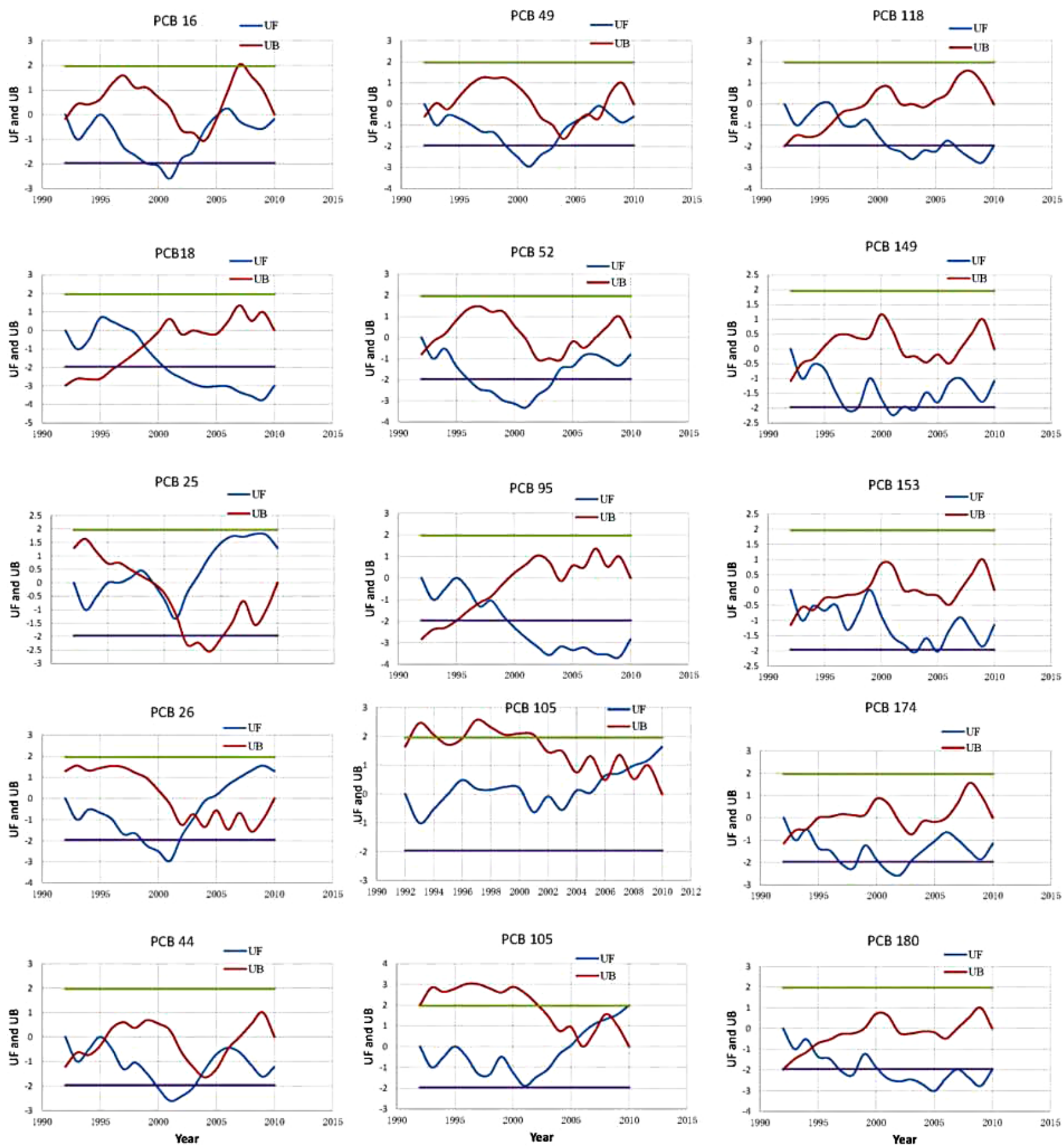

Figure 1. 

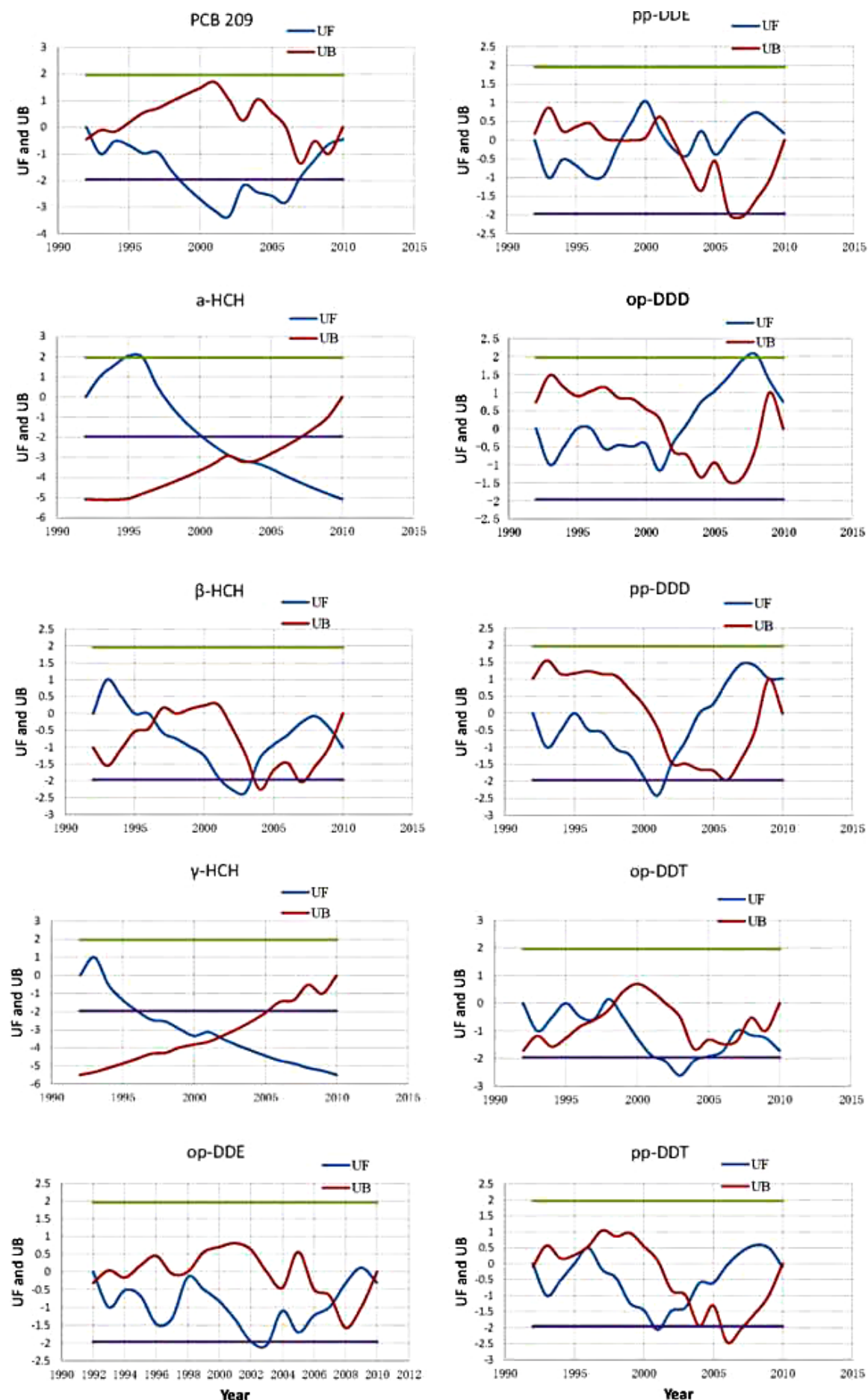

Figure 1. Mann-Kendall (MK) testing statistics for PCBs and OCPs collected from the Alert station (1993-2012). The blue solid line is the forward sequence $U F_{i}$ and the red solid line is the backward sequence $U B_{i}$ defined by Eq. (5). Two straight solid lines stand for confidence interval between -1.96 (straight purple line) and 1.96 (straight green line) in the MK test. The intersection of $U F_{i}$ and $U B_{i}$ sequences within intervals between two confidence levels indicates a step change point. 
Table 1. PCB congeners and OCP isomers having step change points at four arctic monitoring stations detected by the MK test.

\begin{tabular}{llll}
\hline \multicolumn{3}{c}{ Step change point years } \\
\hline \multirow{2}{*}{ Zeppelin } & \multicolumn{2}{c}{$2005-2006$} & $2007-2008$ \\
& $\mathrm{CB}-28,31,33,37,47$, & $\mathrm{CB}-180$ & $\mathrm{CB}-18,28,31,33,37$, \\
& $99,144,156,167,170$, & $47,52,99,101,153$, \\
& $180,183,187,189$, & $156,167,170,183$, \\
& $194,206,209$, & $p, p^{\prime}-\mathrm{DDD}, p, p^{\prime}-\mathrm{DDE}$ \\
& $p, p^{\prime}-\mathrm{DDE}$ & \\
\hline Alert & $\mathrm{CB}-25,26,44, p, p^{\prime}-$ & $\mathrm{CB}-16,49, p, p^{\prime}$-DDE & $\mathrm{CB}-44,49,105,110$, \\
& $\mathrm{DDE}, o, p^{\prime}-\mathrm{DDD}$, & & $o, p^{\prime}-\mathrm{DDE}, o, p^{\prime}-\mathrm{DDT}$ \\
& $p, p^{\prime}-\mathrm{DDD}, p, p^{\prime}$-DDT & & \\
\hline Storhofdi & $\mathrm{CB}-28,31,105,138$, & $\mathrm{CB}-138, \gamma-\mathrm{HCH}$ & $\mathrm{CB}-28,31,52,101$, \\
& 180 & & $118,138,153$ \\
\hline Pallas & $\mathrm{CB}-101,118,138,180$ & $\mathrm{CB}-52,101,153$ & $\mathrm{CB}-28,52,101,118$, \\
& & & 153 \\
\hline
\end{tabular}

\subsubsection{Zeppelin}

Figure 2 illustrates $U F_{i}$ and $U B_{i}$ for $13 \mathrm{PCBs}, \mathrm{HCB}$, and $p, p^{\prime}$-DDT from 1994 to 2012 at the Zeppelin site, derived by the MK test. The intersections between $U F_{i}$ and $U B_{i}$ were identified for these PCBs except for PCB 189. The first intersection occurred between 2001 and 2003, and the second one took place mostly in 2007. Table 1 also presents the MKderived step change point years of 20 PCB congeners and three DDTs isomers at Zeppelin and other arctic sites during the 2000s. The step change points for other OCPs were below the confidence level and hence not accounted here. Although the $U F_{i}$ and $U B_{i}$ sequences lay between the positive and negative confidence levels (1.96 and -1.96$)$ before 2000 and after 2008, no intersections between the two sequences were detected within the confidence levels. Overall, the MK test detected the most step change points of these chemicals for the two periods, spanning from 2001 to 2003 and from 2007 to 2008. Both step changes span approximately a 3-year time period. Eighteen chemicals were found to exhibit step change points for the period of 2001 through 2003 and 21 chemicals were identified to have step change points for the period of 2006 to 2008. Since most PCB data were only available from 1998, their trends and step change points could not be identified in the 1990s. Nevertheless, while the ambient air concentrations of three DDTs isomers are available from 1994, the only step change point year 1997 for $p^{\prime} p$,-DDD was found during the 1990 s by the MK test (Table 1).

\subsubsection{Storhofdi and Pallas}

There are only 10 coeluting PCB congeners reported by Storhofdi station (Hung et al., 2010). The $U F_{i}$ and $U B_{i}$ sequences of 9 PCBs out of 10 , together with $\alpha-, \gamma-\mathrm{HCH}$, and HCB, which fall into the confidence levels from 1995 to
2011, are shown in Fig. S2. The most intersections between the $U F_{i}$ and $U B_{i}$ sequences of the nine PCBs can be found between 2006 and 2008, except for PCB 105 and 180. Other step change points for these PCBs were found in the $1990 \mathrm{~s}$ and the early 2000s (PCB 28, 31, 105, 138, 153, 180, and HCB), as is also shown in Table 1. No step change year for $\alpha-\mathrm{HCH}$ was detected during this period of time, but there was a step change year for $\gamma-\mathrm{HCH}$ in 2007 . HCB exhibited a step change point in 1999. Further details are shown on Table 1.

There are seven coeluting PCB congeners reported by Pallas station. The $U F_{i}$ and $U B_{i}$ of all these seven PCBs fall into the confidence level. The MK statistics of these seven PCB congeners and $\alpha$ - and $\gamma-\mathrm{HCH}$ are illustrated in Fig. S3. Analogous to Zeppelin and Storhofdi stations, the most intersections between $U F_{i}$ and $U B_{i}$ of the reported PCBs were found in 2007 except for PCB 180, which showed the step change year in 2003. Other statistically significant step change years were detected between 2001 and 2003 (PCB 101, 118, 138, and 180) and in 2005 (PCB 52, 101, and 153), as is also shown in Table 1 . Again, although the $U F_{i}$ and $U B_{i}$ of $\alpha$ - and $\gamma$-HCH were intersected in 2003 and 2004, these two intersections were below the confidence level and therefore no step change points for $\mathrm{HCH}$ were accounted for.

\subsection{Step change points identified by MTT and Yamamoto methods}

Considering that in some cases the MK test failed to yield step change point for a time series (Yamamoto et al., 1985), the MTT and Yamamoto methods were further employed in the same data sets of PCBs and OCPs at the four arctic monitoring sites to verify the MK test results and to increase the confidence of detected step change points by the MK test. Figures S4 and S5 in the Supplement show the MTT 

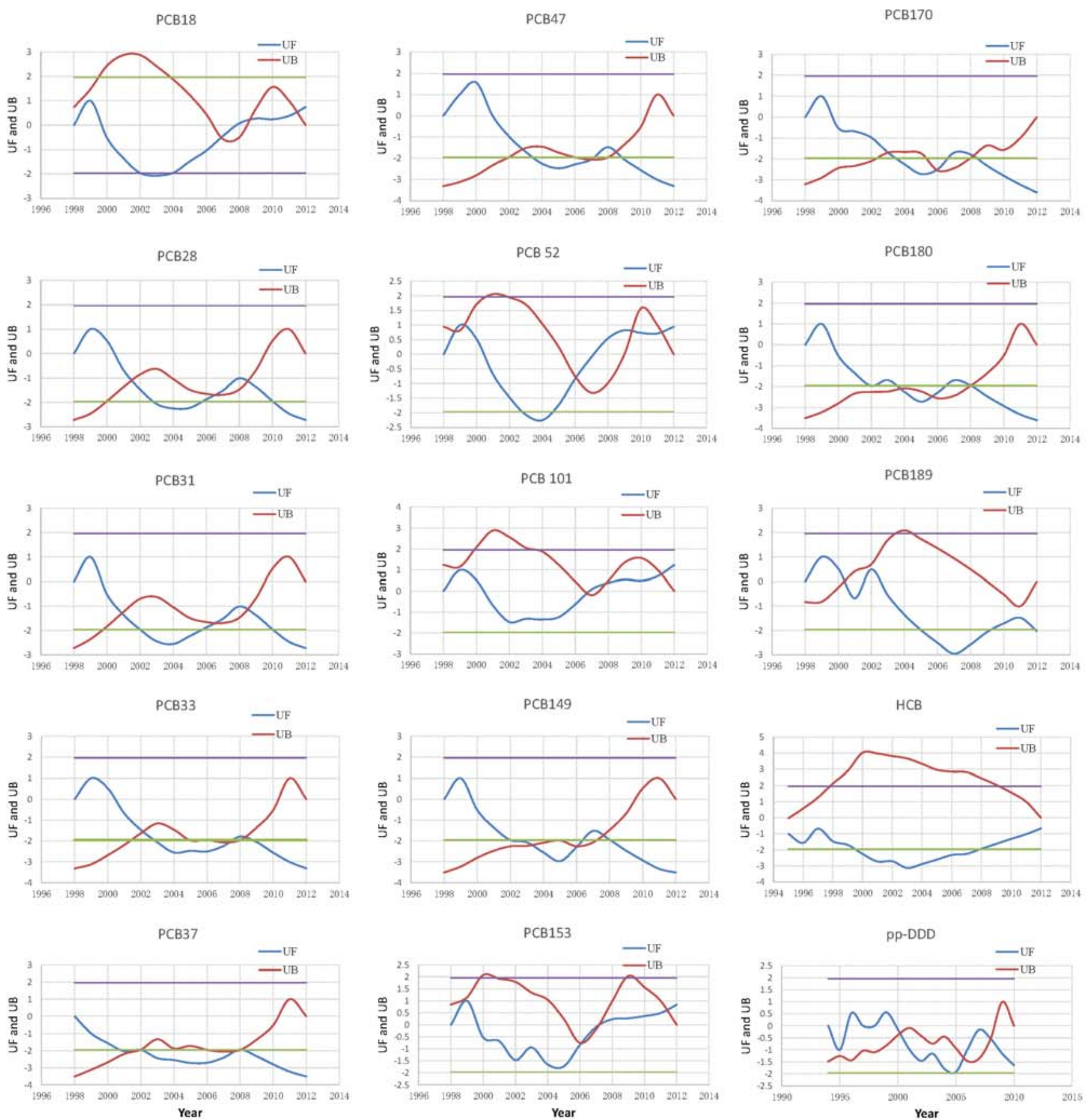

Figure 2. Same as Fig. 1 but for the Zeppelin station (1992-2012).

and Yamamoto statistics for PCB and OCP time series at Storhofdi and Pallas monitoring stations, respectively. Compared with the results from the MK statistics, both the MTT and Yamamoto methods did not detected statistically significant step change points in 2007 for most PCBs and OCPs at Pallas. The MTT method detected the step change point around 2000 for penta-PCB (PCB 101 and 118) and hexaPCB (PCB 138 and 153) and from 2007 to 2008 for penta-
PCB. Step changes in $\alpha$ - and $\gamma$-HCH were found between 2000 and 2002 and in 2005. Yamamoto method only detected a step change year around 2000 for PCB 138 but, analogous to the MTT method, found the step change between 2000 and 2002 for the two HCH isomers. Both MTT and Yamamoto methods detected the step change in 2001 for PCB 101 and 2003 for PCB 105 but only found the 2007 as the step change 

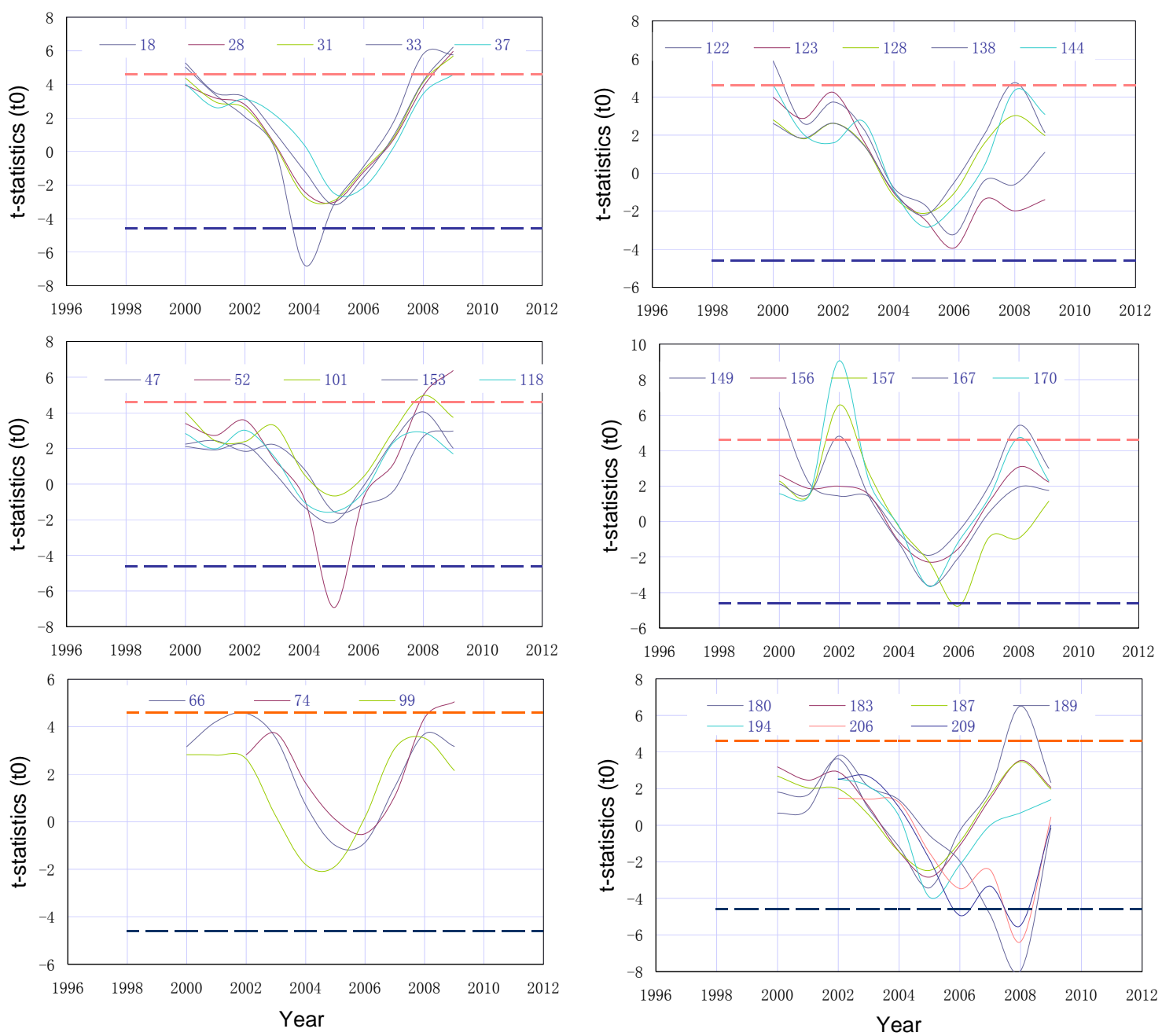

Figure 3. Moving $t$ test statistics for ambient annual mean air concentrations of 30 PCBs collected at the Zeppelin station (1992-2012).

year for PCB 52 and $\alpha-\mathrm{HCH}$, respectively (Fig. S5 in the Supplement).

Figure 3 shows the MTT statistics for 30 PCBs at Zeppelin station. The MTT statistics for these PCBs illustrate a "V" pattern except for several heavier PCBs. All tri-PCBs exhibited the step change year in 2008. The same step change year was also found for PCB 52, 74, 101, 138, 149, 170, and 180. The step change year 2008 for these PCBs derived from the MTT method lagged 1 year behind the step change year (2007) detected by the MK test (Fig. 1 and Table 1). However, this step change year (2008) can be regarded as an extension of the step change year 2007 because the step change year 2007 by the MK test is an onset year of step change. Other step change years were detected in 2000, 2002, and 2005 but for only several PCBs out of 30 PCB congeners. The MTT statistics for OCPs did not show any wellorganized pattern like for PCBs (figures not shown). The step change points of OCPs varied with different chemicals, but 1999 and 2003 appeared to be the most detected step change years among these OCPs. The Yamamoto statistics also displayed peak values and step changes in 2008 for many PCBs, followed by 2000 and 2002 (results not shown). Tables S4 and S5 in the Supplement present the step change years for PCBs and OCPs at the Zeppelin site computed by the MTT and Yamamoto methods.

The results from the MTT and Yamamoto statistics for 20 PCBs at Alert are illustrated in Fig. 4 and also presented in Tables S4 and S5 in the Supplement. Both the MTT and Yamamoto methods yielded a step change point in 2006 for several PCBs, notably PCB 16A, 25, 44, 118, 174, and 209. The MTT method detected the step change year in 2005 for both $\alpha$ - and $\gamma-\mathrm{HCH}$, while the Yamamoto method only found this step change year for $\alpha-\mathrm{HCH}$ (Tables S4 and S5). Nevertheless, this step change year for HCHs was not discerned by the MK test, as illustrated previously. The two methods also detected the step change year for $p, p^{\prime}$-DDE in 2000, which was consistent with the step change year detected by the MK 

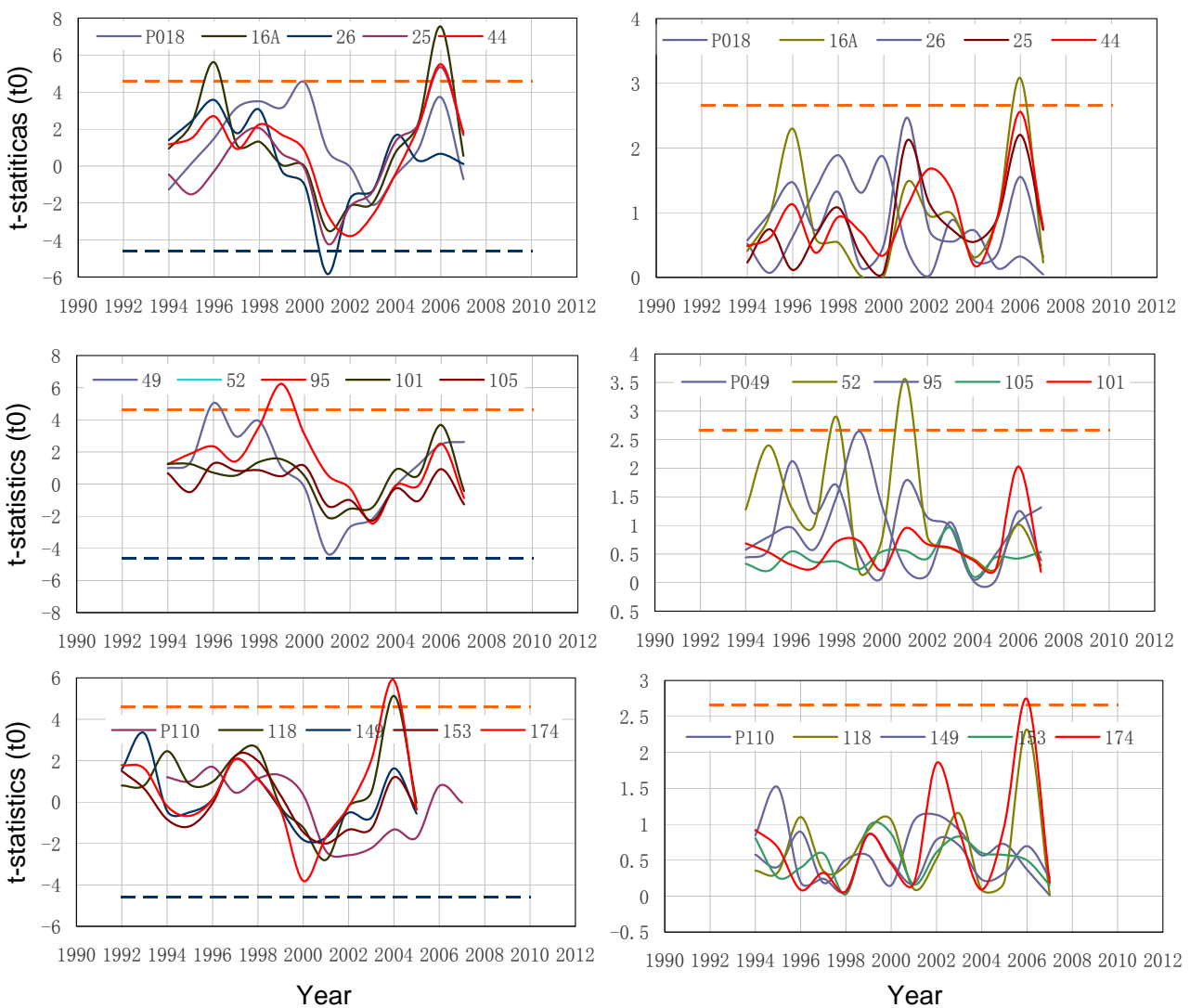

Figure 4. Moving $t$ test (left panel) and Yamamoto (right panel) statistics for annual mean ambient air concentrations of 20 PCBs collected at Alert station (1993-2012).

test, and in 2001 for $p, p^{\prime}$-DDD, leading the MK test result (2002) by 1 year.

\section{Discussions}

To summarize the step change points for selected chemicals at the four arctic atmospheric monitoring sites, we first selected those PCBs and OCPs whose step point years were identified by the MK test and confirmed by one of the other two methods. Results show that for Alert, the statistically significant step change year detected by the MK test and the MTT or Yamamoto method was only found in 2005-2006 for PCB 16 and 44, respectively. While the MK test also identified the same step change in PCB 49, 105, and 110 during this period of time (Fig. 1), this step change was not detected by the other two methods (Fig. 4). The step change years in OCPs detected by the MK test were not confirmed by the MTT and Yamamoto method either. In the MK test, $U F_{i}$ (the forward sequence, Eq. 5) was often used to represent the trend of a time series. At Alert, the $U F_{i}$ values of lighter PCBs (tri-PCBs and PCB 44) showed an increasing trend and a negative to positive reversal since 2005. In fact, almost all intersections between $U F_{i}$ and $U B_{i}$ of these lighter $\mathrm{PCBs}$, indicating the step change, took place when $U F_{i}$ be- came positive, confirming the increasing trend of these lower molecular PCBs measured at Alert during the mid-2000s, whereas heavier PCBs did not show significant increasing trend for the same period of time.

The step change years detected by the MK test and the MTT or Yamamoto method at Storhofdi include 2007 for PCB 52 and 2003 for PCB 105, respectively (Fig. S2 and S4). Among the measured PCBs, the $U F_{i}$ values of PCB 52, 101, and 118 exhibited an increasing trend since 1998-2000. Such an increasing trend was not observed in $U F_{i}$ values in other PCBs and OCPs.

At Pallas site, the MK test and MTT or Yamamoto method found the step change year 2001 for PCB 118 and 138 and 2007 for PCB 101 and 108, respectively (Figs. S3 and S5). The $U F_{i}$ did not show significant increasing trend for all PCBs and OCPs.

The MTT method confirmed the step change year in most PCBs in 2007 at Zeppelin calculated by the MK test, except for PCB 47, 153, and 180 (Figs. 2 and 3). Another step change year in 2002-2003 for several PCBs detected by the MTT method was also consistent, to some extent, with that derived from the MK test. As shown by Fig. 2, the $U F_{i}$ values of many PCBs showed an increasing trend from the early and mid-2000s and reached the maximum for 2007-2008, 
Table 2. PCB congeners with step change points at four arctic monitoring stations detected by the MK test and moving $t$ test or Yamamoto method.

\begin{tabular}{llll}
\hline \multicolumn{3}{c}{ Step change point years } \\
\hline & $2001-2003$ & 2005-2006 & 2007-2008 \\
\hline Zeppelin & CB-18, 28, 33, & CB-18, 28, 31, \\
& $37,170,189$ & $33,37,52,101$, \\
& & $149,170,180$ \\
\hline \multirow{2}{*}{ Alert } & & CB-16A, 44 \\
\hline Storhofdi & CB-28,31 & & CB-52 \\
\hline Pallas & CB-118,138 & CB-101,108 \\
\hline
\end{tabular}

again agreeing with the measured trend of ambient atmospheric concentrations of these PCBs.

Table 2 summarized the step change years for PCBs and OCPs at the four arctic atmospheric monitoring sites discerned simultaneously by the MK test and the MTT or Yamamoto method. Overall, although the step changes years varied with different chemicals and monitoring sites, these step change points all took place in the 2000s. Furthermore, although individual statistical methods did identify the step changes in OCPs, these changes were not detected simultaneously by two out of the three statistical methods used in the present study. Among the three periods of 2001-2003, 20052006, and 2007-2008 listed in Table 2, the step change point was found in the highest number of monitored chemicals for the period of 2007-2008, followed by 2001-2003 and 20052006. Although 2005-2006 and 2007-2008 are two adjacent periods, the step changes in POP concentrations during these two periods might show their distinct response to marked decline of sea ice concentrations in 2005 and 2007, as shown in Fig. 5. Another common feature from the MK test was that the forward sequence $U F_{i}$ for many PCBs showed an increasing trend from 2000, as illustrated by Figs. 1, 2, S2, and S3.

The causes for the existence of those step change points in monitored POP time series at the different arctic sites are complex. They depend on locations of the monitoring sites, chemical-physical properties of individual chemical, changes in arctic sea ices and air temperatures which are nonuniform across the Arctic, and others. Our statistical tests showed that the step change points were mostly detected in PCBs. This is likely related to their relatively higher Henry's law constants, ranging from $4.4 \mathrm{~Pa} \mathrm{~m}^{-3} \mathrm{~mol}^{-1}$ for PCB 194 to $33.9 \mathrm{~Pa} \mathrm{~m}^{-3} \mathrm{~mol}^{-1}$ for PCB 31 (Li et al., 2003), as compared with other chemicals (e.g., DDTs and $\mathrm{HCHs}$ ), indicating higher tendencies for volatilization from water/ice to air. The ambient atmospheric concentrations of HCB at Zeppelin, which has higher Henry's law constant (=65 $\mathrm{Pa} \mathrm{m}^{-3} \mathrm{~mol}^{-1}$; Shen and Wania, 2005), also showed an increasing trend from 2003 (Fig. 2). This increasing trend

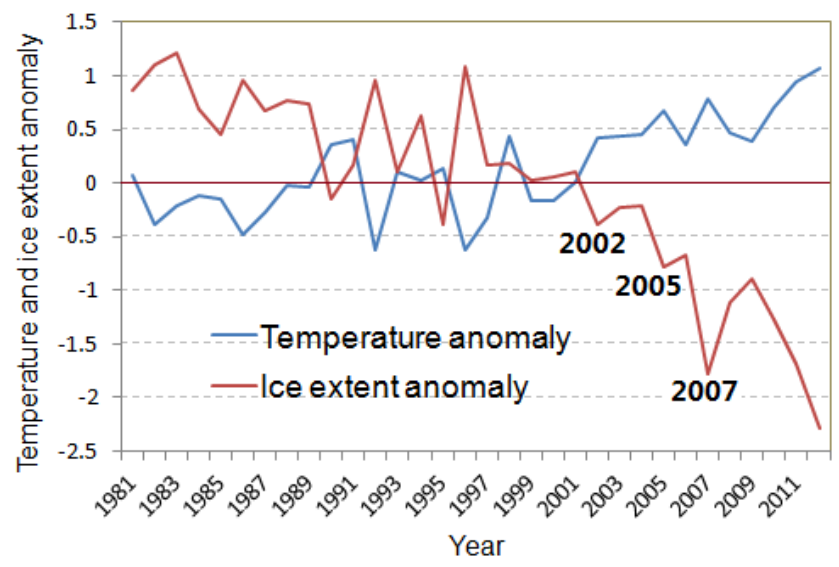

Figure 5. Mean summer temperature (K; July-September, 19812012) averaged over the Arctic as the departures from 1950 to 2010 mean (NCEP reanalysis; Kalney et al., 1996) and sea ice extent (July-September, $10^{7} \mathrm{~km}^{2}$ ) anomalies from 1981 to 2012, averaged over the Arctic as the departures from 1979 to 2010 mean, manipulated from NSIDC data (Clark, et al., 1999).

has been attributed to changes in source types and the presence of impurities in currently used pesticides as well as sea ice retreat (Hung et al., 2010; Becker et al., 2012). However, no step change point for HCB in our statistical analysis was detected, though this substance exhibited a clear increasing trend in the mid-2000s at the Zeppelin site. This might be attributed to the strong persistence of HCB in the air, which led to less significant declining in the Arctic over the last two decades (Hung et al., 2010). The increasing HCB concentrations in the mid-2000s were not significant enough to yield a "step change" from its weak decreasing trend before the mid-2000s.

Results presented on Tables 1 and 2 also show more PCB congeners with statistically significant step change points at Zeppelin than at Alert. Compared with the Zeppelin monitoring site, which is located on the western coast of Spitsbergen (Svalbard, Norway), the Alert station experiences lower temperatures, is surrounded by rugged hills and valleys, and hence is less affected by sea ice retreat and open waters. In addition, as shown by Fig. 1 and Table 1, the step change points in several PCBs and DDTs were detected in 20012003 by the MK test. Due to laboratory switching in 2002, which led to increasing air concentrations of monitored POPs after 2002 (Hung et al., 2010), the step changes in POPs from 2001 to 2003 at Alert might be also subject to laboratory switching.

The both temporal and spatial patterns of POPs in arctic air have been attributed to various processes driven by climate-induced changes in the arctic environment, such as reduced ice cover, increasing air and seawater temperatures, and biomass burning in boreal regions (Hung et al., 2010; Ma et al., 2011; Becker et al., 2012). Since the step changes in POPs are unlikely to be associated with interannual cli- 
mate variability (e.g., NAO, ENSO) and biomass burning (which should affect primarily the seasonal or interannual alteration in POPs), these step changes were anticipated to be fluctuations in the long-term trend in POP time series. The statistically significant step change point years for PCBs in the present study appeared to coincide with those years during which arctic sea ice exhibited marked decline. Figure 5 shows the mean summer temperature and sea ice extent anomalies from 1981 to 2012 averaged over the Arctic as the departures from their means over 1950 to 2010 and 1979 to 2010 , respectively. It can be seen that the mean sea ice extent declined in the summer of 2002, 2005, and 2007. In particular, the mean summer sea ice extent exhibited a decreasing trend and has been negative since 2001. This result agreed with a previous report which showed that, during the 2000s, the arctic sea ice September minimum extent (i.e., area with at least $15 \%$ sea ice coverage, $10^{7} \mathrm{~km}^{2}$ ) reached new record lows in 2002, 2005, and 2007 (http://earthobservatory.nasa. gov/Features/WorldOfChange/sea_ice.php). Accordingly, a negative to positive transition of the mean air temperature anomalies averaged over the Arctic took place since 2001, as also shown in Fig. 5. In particular, summer ice extent in 2007 was about $33 \%$ below the 1979-2013 average, breaking all previous low ice extent records. Our calculated step change points of 2007 through 2008 for many PCBs matched well with this strong decline of the sea ice extent for this period of time.

Since sea ice melting is a crucial factor for controlling the environmental fate of POPs in the Arctic under a warming climate (Becker et al., 2012; Grannas et al., 2013) and the associations between the step changes in ambient atmospheric concentrations and sea ice concentrations, it is worthwhile to elucidate the response of POPs to arctic warming and sea ice fluctuation and melting. We simulated perturbed air concentration $\left(\mathrm{pg} \mathrm{m}^{-3}\right)$ of PCB 28,153 , and $\alpha-\mathrm{HCH}$ subject to water-air and ice-air exchange processes from 1995 to 2012 using the perturbation model (Ma and Cao, 2010; Ma et al., 2011). Considering that the most prominent arctic sea ice melting occurs from July to September, in the simulation we employed mean sea ice volume and area during this season averaged over the Arctic. Air temperature (K) and precipitation $\left(\mathrm{mm} \mathrm{yr}^{-1}\right)$ anomalies used in the perturbation modeling for the same period were also adopted in the modeling. The mean concentrations in air, water, and sea ice used in perturbation modeling are presented in Table $\mathrm{S} 1$ in the Supplement. The perturbed concentrations of the three chemicals averaged over the Arctic are displayed in Fig. 6. As shown, perturbed concentrations of all three chemicals correlated inversely with the mean sea ice anomaly. It is evident that the perturbed concentrations of PCB 28 and 153 illustrated a statistically significant increasing trend during the period of 1995 through 2012. While there was also an increasing trend of $\alpha-\mathrm{HCH}$, this trend was not statistically significant. Opposite to the sea ice extent whose anomalies become negative from 2001, perturbed concentrations of PCB

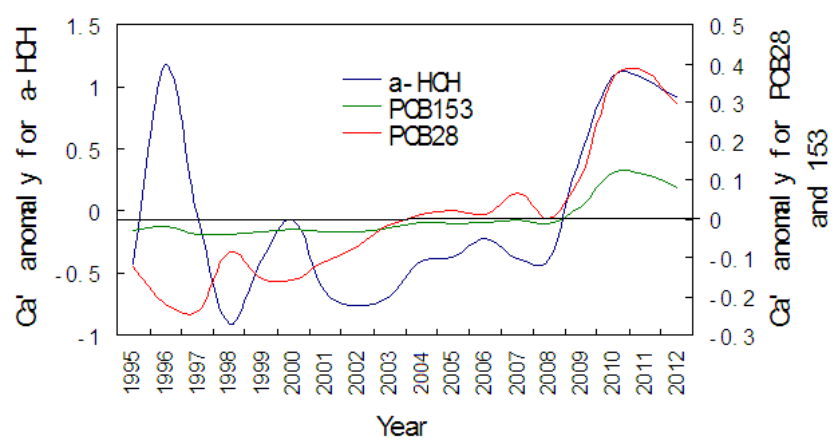

Figure 6. Modeled perturbed air concentration $\left(\mathrm{Ca}^{\prime}, \mathrm{pg} \mathrm{m}^{-3}\right)$ of PCB 28, 153, and $\alpha-\mathrm{HCH}$ from 1995 to 2012. $C_{\mathrm{a}}^{\prime}$ of PCB 28 and 153 is scaled on the right $y$ axis and perturbed air concentration of $\alpha-\mathrm{HCH}$ is scaled on the left $y$ axis. The mean concentrations in air, water, and sea ice of the three chemicals used in perturbation are presented in Table S1 and their physical-chemical properties are presented in Table $\mathrm{S} 2$.

28 turned positive from 2003 after the first step change point year (2001) of this PCB congener (Table 1); the negative to positive reversal of perturbed concentration of the other two chemicals (PCB 153 and $\alpha-\mathrm{HCH}$ ) took place in 20072008, during which the Arctic recorded lowest sea ice extent. The concentration perturbations trend of PCB 28 exhibited a much steeper slope at $0.031\left(R^{2}=0.809\right)$ compared to that of PCB 153 (slope $=0.008, R^{2}=0.626$ ), suggesting that lighter PCBs respond more strongly to arctic sea ice melting. Since model-simulated concentration perturbations via the ice-air exchange process were about 1 order of magnitude lower than that through the water-air exchange in the present study (results not shown), the integrated perturbed concentrations were mostly driven by the water-air exchange. As previously mentioned, the monitored atmospheric concentrations of many PCBs across the Arctic have already shown an increasing trend around 2007, potentially the result of outgassing from the Arctic Oceans due to sea ice retreat (Hung et al., 2010; Becker et al., 2012). Since the perturbed concentrations discern largely the climate change signals in POP time series associated with temperatures and sea ice, it might not be appropriate to compare the step change points in the time series of perturbed concentrations with measured annual mean air concentrations. The latter are driven primarily by emissions and degradation. Nevertheless, the perturbed air concentrations of many PCBs examined in the present study showed the step change in 2001 (Fig. S6), the first step change point of monitored PCB atmospheric concentrations (Tables 1 and 2), and the year when the mean summer temperature and sea ice extent anomalies over the Arctic change their signs (Fig. 5).

Compared with the measured ice concentration used in the present study ( $0.1 \mathrm{ng} \mathrm{L}^{-1}$, Table S1), higher levels of $\alpha-\mathrm{HCH}$ $\left(0.31 \mathrm{n} \mathrm{L}^{-1}\right)$ in sea ice at a high Canadian Arctic site in Beaufort Sea during 2007-2008 were reported by Pućko et 
al. (2010). They also measured $\alpha-\mathrm{HCH}$ in sea ice brine and expected that arctic sea ice changes associated with climate change would make the brine concentration pathway more widespread in the future Arctic Ocean. To test the potential influence of higher $\alpha-\mathrm{HCH}$ concentrations in sea ice and sea ice brine on the fluctuation and temporal trend of this chemical over the Arctic air, we adopted the measured $\alpha-\mathrm{HCH}$ concentrations in sea ice and sea ice brine by Pućko et al. (2010) as the mean concentrations in the perturbation model and integrated the model from 1995 to 2012. Figure S7 compared the perturbed $\alpha-\mathrm{HCH}$ concentrations in air and ice due to air-ice exchange from 1995 to 2012 using the data in Table S1 and Pućko et al. (2010). As expected, the model input is higher mean concentrations of $\alpha-\mathrm{HCH}$ in sea ice and ice brine increase the magnitude of perturbed annual concentrations in air and ice but do not alter their fluctuations and long-term trend. This suggests again that the changes in temperature dominate the fluctuations of perturbed $\alpha-\mathrm{HCH}$ concentrations over the Arctic.

The rapid decline of arctic sea ice in 2007 has triggered the debate that abrupt climate change in the Arctic and low summer sea ice area were likely persistent on a decadal (climate change) timescale. Given that the environmental fate of the selected POPs in the Arctic has been dominated by their primary emission and outgassing from their reservoirs accumulated from past use, deposition, and long-range transport from atmosphere and oceanic currents (Macdonald et al., 2005; Gioia et al., 2008; Hung et al., 2010; Kallenborn et al., 2012; Wöhrnschimmel et al., 2013), atmospheric levels of many POPs in the Arctic have been declining over the last decades after their regulation and phaseout. Previous modeling investigations (Lamon et al., 2009; Wöhrnschimmel, et al., 2013) have revealed that the maximum changes in POP atmospheric concentrations induced by climate change were driven mostly by climate-warming-forced potential changes in primary emission. This appeared to suggest that the POP outgassing from their arctic repositories associated with arctic warming and sea ice retreat would not change their long-term declining trend because the emission and degradation overwhelmed the POP long-term declining trend. However, as previously mentioned, the measured ambient POP air concentrations in the mid-2000s did not follow the declining trend driven by primary emissions and degradations. The perturbation modeling was aimed at assessing major processes contributing to concentration anomalies as the departure from the mean POP concentrations driven mostly by their primary emission and degradation. We have demonstrated that the temperature-dependent emission (Eqs. 8 and 9) could alter the magnitude of modeled concentration perturbations but not change long-term trend and interannual variation of the perturbed concentrations (Ma and Hung, 2012). The perturbed (rather than measured) POP air concentrations were, therefore, forced largely by the outgassing from their reservoirs in melting ice (snow) and the Arctic oceans. In this context, a reversal of many POPs from deposi- tion to volatilization associated potentially with arctic warming and sea ice retreat would likely take place. To examine this argument, we estimated perturbed water-air and ice-air exchange flux (ng m $\left.{ }^{-2} \mathrm{~s}^{-1}\right)$ of the three selected chemicals (PCBs-28, 153, and $\alpha-\mathrm{HCH}$ ). Results show that the modeled water-air exchange flux perturbations of the three selected chemicals exhibited similar trend and interannual variability. So in Fig. 7 we only present perturbed water-air exchange flux of PCB 28 and $\alpha-\mathrm{HCH}$. As shown, the modeled exchange flux perturbations of PCB 28 were negative over the 1990s except for 1998, indicating deposition of perturbed PCB 28. From 2001 onward, the perturbed flux turned to positive and exhibited a clear increasing trend with greater values in 2007 and after 2010, implying climate-change-forced revolatilization of this PCB congener. The perturbed waterair exchange fluxes of $\alpha-\mathrm{HCH}$ were positive throughout the modeling period of 1995 through 2012, except for 1996. This agrees with previous modeling results which predicted the reversal of the exchange direction of $\alpha-\mathrm{HCH}$ from deposition to volatilization in the Arctic Ocean in the early 1990s (Wania and Mackay, 1999; Wania et al., 1999). Compared with the mean air concentration of PCB 28 at $3 \mathrm{pg} \mathrm{m}^{-3}$, the modeled maximum perturbed concentration of PCB 28 due to water-air and ice-air exchange was $0.25 \mathrm{pg} \mathrm{m}^{-3}$, about $8 \%$ of the mean. For PCB 153, the modeled maximum perturbed concentration was almost $30 \%$ of the mean (Table S1 in the Supplement), showing a stronger response of this PCB congener to the change in the arctic environment. However, the modeled maximum perturbed $\alpha-\mathrm{HCH}$ concentration was only $5 \%$ of its mean concentration (Table S1 in the Supplement). The perturbation of POP air concentrations at this magnitude induced by sea ice retreat and snow melting should not be overlooked. If there was indeed the onset of an abrupt arctic climate change "tipping" point, continuous decline of arctic sea ice in the forthcoming years may lead to stronger release of POPs into arctic air. As shown in Fig. 7, both perturbed air concentrations and water-air exchange fluxes of PCB 28 become positive after 2001 with relatively large values in 2007, coinciding with these 2 years during which many PCBs showed the onset of step changes and the arctic sea ice extents reduced considerably (Figs. 1, 2, S2, S3, and Table 2).

The modeled annual ice-air exchange flux perturbations of two PCBs averaged over the Arctic also showed similar trend and interannual variation. The exchange fluxes of PCB 28 were positive throughout the modeling period (1995-2012), indicating outgassing. The fluxes of the other two chemicals were negative. To illustrate ice-air exchange, Fig. 8 displays perturbed ice-water exchange fluxes $\left(\mathrm{ng} \mathrm{m}^{-2} \mathrm{~s}^{-1}\right)$ of three chemicals. The flux perturbations of PCB 28 and 153 show an increasing trend and the negative to positive reversal in 2007, the year of the potential onset of abrupt arctic climate change "tipping" point (Livina and Lenton, 2013). Differing from its water-air exchange flux, the annual mean ice-air exchange flux perturbation of $\alpha-\mathrm{HCH}$ averaged over the Arc- 


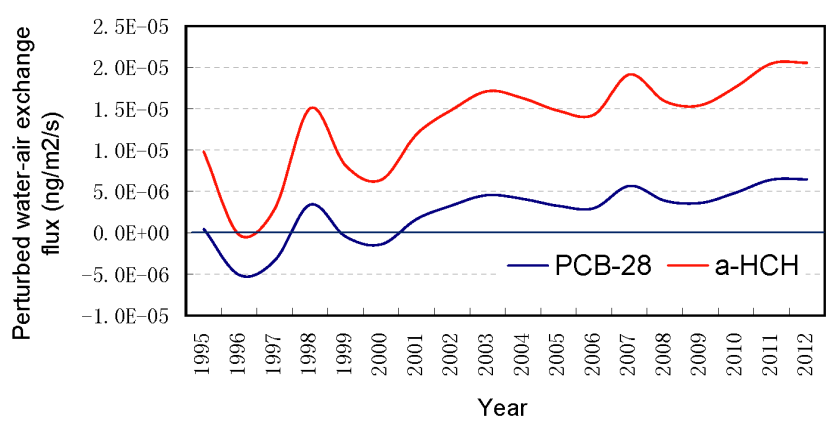

Figure 7. Simulated water-air exchange flux perturbations $\left(\mathrm{ng} \mathrm{m}^{-2} \mathrm{~s}^{-1}\right.$ ) of PCB 28 and $\alpha-\mathrm{HCH}$ from 1995 to 2012.

tic decreased from the 1990s. It is not clear if the stronger response of PCB 28 to sea ice retreat characterized by its step changes in 2001 and 2007 at the Zeppelin station (Table 2, Figs. 2 and 3) could be attributed to its outgassing from melting sea ice and glaciers as compared with PCB 153 and $\alpha-\mathrm{HCH}$. The latter two chemicals showed negative exchange fluxes, indicating deposition. Accordingly, there were no step change points for these two chemicals in 2001 and 2007 (Table 2). While the releasing from melting ice may increase air concentrations, it would also lead to increased potential for air to sea transfer (Gioia et al., 2008), characterized by the negative flux. Overall, our results showed that the perturbed ice-air exchange fluxes were lower than the water-air fluxes in arctic environment. Since the molded water-air exchange flux perturbations were positive, which might increase air concentrations, these increasing air concentrations from the water-air exchange may lead to deposition in the ice-air exchange, as interpreted by Gioia et al. (2008). POPs releasing from seasonal melting snow pack and mountain glaciers have been demonstrated to significantly change the environmental fate of POPs (Stocker et al., 2007; Bogdal et al., 2009; Meyer and Wania, 2008). Previous studies in this aspect almost entirely focused on the effect of seasonal changes in sea ice melting on POP environmental fate (Daly and Wania, 2004; Gioia et al., 2008; Jantunen et al., 2007; Wong et al., 2010). Little is known about the change in the long-term environmental fate of POPs in the Arctic induced by interannual- or decadal-scale sea ice variation. It should be noted that, due to very sparse POP measurements in sea ice and glaciers across the Arctic, the mean ice concentrations we input to the perturbation model may have large errors which could even alter the exchange direction in modeled fluxes. Using the sampled $\alpha-\mathrm{HCH}$ concentrations in air, water, and brine from Pućko et al. (2010) collected in the Canadian High Arctic we have simulated the perturbed air-brine gas phase exchange flux of $\alpha-\mathrm{HCH}$ and compared the result with the perturbed air-ice exchange fluxes using the data presented in Table S1. It was found that, though the two time series of the perturbed fluxes exhibited the same fluctuation and trend driven by temperatures and sea ice extents, the air-brine exchange fluxes were

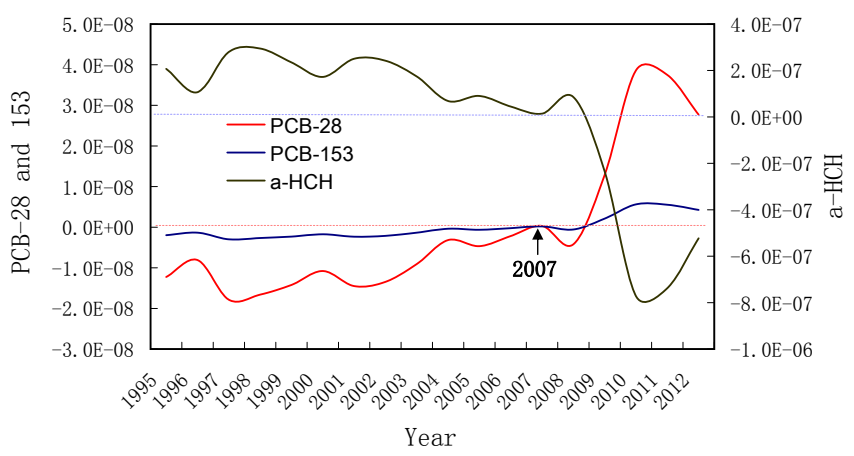

Figure 8. Simulated ice-air exchange flux perturbation $\left(\right.$ ng m ${ }^{-2} \mathrm{~s}^{-1}$ ) of three selected chemicals from 1995 to 2012. Perturbed fluxes of PCB 28 and 153 are scaled on the left $y$ axis and $\alpha-\mathrm{HCH}$ flux perturbation is scaled on the right $y$ axis. Blue dished line stands for the case for $\alpha-\mathrm{HCH}$ flux perturbation $=0$ and pink dashed line stands for the case for PCB 28 and 153 flux perturbation $=0$.

several orders of magnitude greater than the air-ice fluxes and did not switch from positive to negative as shown in perturbed air-ice flux, which turned from positive to negative from 2008 (Fig. 8).

\section{Conclusions}

After their phaseout, many legacy POPs have been and will be still declining in the Arctic environment in forthcoming years. An increasing trend of POP atmospheric concentrations under strong warming and sea ice melt across the Arctic is unlikely to take place as comparing with continuously increasing trend of arctic temperature. However, there is likely a "turning point" for these POPs in the context of climate change. From this year onward, arctic warming influence on POP trend may become relatively stronger. In other words, there would be stronger arctic climate change "signals" in monitored ambient POP concentrations data after this turning point. Our statistical test identified two major step change points in the measured PCB time series, coincident with the onset of rapid arctic sea ice melting after 2001. Our perturbation modeling suggested that the periods of 2001-2002 and 2007-2008 were likely the "turning points" for PCBs in arctic air, as demonstrated by the reversal of deposition to outgassing of the perturbed water-air exchange flux and negative to positive transition in the modeled air concentration perturbations of the selected chemicals. In particular, from the second step change point year (2007-2008) onward identified in the present study, we would expect that the effect of arctic climate change on POP environmental fate would become more detectable. This is supported partly by the increasing air concentrations of many PCBs measured at the Zeppelin and Alert sites (Hung et al., 2010). The finding from the present study not only discerned the abrupt cli- 
mate change signatures in measured time series of POP atmospheric concentrations but also provided additional evidence for the response of arctic environment and ecosystem to arctic climate change.

\section{The Supplement related to this article is available online at doi:10.5194/acp-15-3479-2015-supplement.}

Acknowledgements. We would like to acknowledge all site and laboratory operators and students of the air monitoring programs that make long-term data available. This research was supported by the National Science Foundation of China (grants 41371478 and 41371453).

Edited by: L. Zhang

\section{References}

Armitage, J. M., Quinn, C. L., and Wania, F.: Global climate change and contaminants - an overview of opportunities and priorities for modelling the potential implications for long-term human exposure to organic compounds in the Arctic, J. Environ. Monit., 13, 1432-1546, 2011.

Becker, S., Hallsell, C. J., Tych, W., Kallenborn, R., Su, Y., and Hung, H.: Long-term trends in atmospheric concentrations of $\alpha$ and $\gamma-\mathrm{HCH}$ in the Arctic provide insight into the effects of legislation and climatic fluctuations on contaminant levels, Atmos. Environ., 42, 8225-8233, 2008.

Becker, S., Halsall, C. J., Tych, W., Kallenborn, R., Schlabach, M., and Man $\varnothing$, S.: Changing sources and environmental factors reduce the rates of decline of organochlorine pesticides in the Arctic atmosphere, Atmos. Chem. Phys., 12, 4033-4044, doi:10.5194/acp-12-4033-2012, 2012.

Bidleman, T. F. and McConnell, L. L.: A review of field experiments to determine air-water gas exchange of persistent organic pollutants, Sci. Total Environ., 159, 101-117, 1995.

Bogdal, C., Schmid, P., Zennegg, M., Anselmetti, F. S., Scheringer, M., and Hungerbuhler, L. K.: Blast from the past: melting glaciers as a relevant source for persistent organic pollutants, Environ. Sci. Technol., 43, 8173-8177, 2009.

Breivik, K., Sweetman, A., Pacyna, J. M., and Jones, K. C.: Towards a global historical emission inventory for selected PCB congeners - a mass balance approach, 3. An update, Sci. Total Environ., 377, 296-307, 2007.

Clark, P. U., Alley, R. B., and Pollard, D.: Northern Hemisphere icesheet influences on global climate change, Science, 286, 11041111, 1999.

Daly, G. L. and Wania, F.: Simulating the influence of snow on the fate of organic compounds, Environ. Sci. Technol., 38, 41764186, 2004.

Duarte, C. M., Lenton, T. M., Wadhams, P., and Wassmann, P.: Abrupt climate change in the Arctic, Nature Clim. Change, 2, 60-64, 2012.

Gan, T. Y.: Hydroclimatic trends and possible climatic warming in the Canadian Prairies, Water Resour. Res., 34, 3009-3015, 1998.
Gao, H., Ma, J., Cao, Z., Dove, A., and Zhang, L.: Trend and climate signals in seasonal air concentration of organochlorine pesticides over the Great Lakes, J. Geophys. Res., 115, D15307, doi:10.1029/2009JD013627 2010.

Gioia, R., Lohmann, R., Dachs, J., Temme, C., Lakaschus, S., Schulz-Bull, D., Hand, I., and Jones, K. C.: Polychlorinated biphenyls in air and water of the North Atlantic and Arctic Ocean, J. Geophys. Res., 113, D1930, doi:10.1029/2007JD009750 2008.

Gouin, T., Armitage, J. M., Cousins, I. T., Muir, D. C., Ng, C. A., Reid, L., and Tao, S.: Influence of global climate change on chemical fate and bioaccumulation: the role of multimedia models, Environ. Toxicol. Chem., 32, 20-31, 2013.

Grannas, A. M., Bogdal, C., Hageman, K. J., Halsall, C., Harner, T., Hung, H., Kallenborn, R., Klán, P., Klánová, J., Macdonald, R. W., Meyer, T., and Wania, F.: The role of the global cryosphere in the fate of organic contaminants, Atmos. Chem. Phys., 13, 32713305, doi:10.5194/acp-13-3271-2013, 2013.

Holland, M. M., Bitz, C. M., and Tremblay, B.: Future abrupt reductions in the summer Arctic sea ice, Geophys. Res. Lett., 332, L2350, doi:10.1029/2006GL028024 2006.

Hung, H., Blanchard, T. P., Halsall, C. J., Bidleman, T. F., Stern, G. A., Fellin, P., Muir, D. C. G., Barrie, L. A., Jantunen, L. M., Helm, P. A., Ma, J., and Konoplev, A.: Temporal and spatial variabilities of atmospheric polychlorinated biphenyls (PCBs), organochlorine (OC) pesticides and polycyclic aromatic hydrocarbons (PAHs) in the Canadian Arctic: Results from a decade of monitoring, Sci. Total Environ., 342, 119-144, 2005.

Hung, H., Kallenborn, R., Breivik, K., Su, Y., Brorström-Lundén, E., Olafsdottir, K., Thorlacius, J., M., Leppänen, S., Bossi, R., Skov, H., Manø, S., Patton, G., W., Stern, G., Sverko, E., and Fellin, P.: Atmospheric monitoring of organic pollutants in the Arctic under the Arctic Monitoring and Assessment Programme (AMAP), Sci. Total Environ., 408, 1993-2006, 2010.

Jantunen, L. M., Helm, P. A., Kylin, H., and Bidleman, T. F.: Hexachlorocyclohexanes (HCHs) In the Canadian Archipelago, 2. Air-water gas exchange of $\alpha$ - and $\gamma-\mathrm{HCH}$, Environ. Sci. Technol., 42, 465-470, 2007.

Kallenborn, R., Halsall, C., Dellong, M., and Carlsson, P.: The influence of climate change on the global distribution and fate processes of anthropogenic persistent organic pollutants, J. Environ. Monit., 14, 2854-2869, 2012.

Kalney, E., Kanamitsu, M., Kistler, R., Collins, W., Deaven, D., Gandin, L., Iredell, L., Saha, S., White, G., Woollen, J., Zhu, A., Leetmaa, Y., Reynolds, R., Chelliah, M., Ebisuzaki, W., Higgins, W., Janowiak, J., Mo, K.C., Ropelewski, C., Wang, J., Jenne, R. and Joseph, D.: The NCEP/NCAR reanalysis project, B. Am. Meteorol. Soc., 77, 437-471, 1996.

Kendall, M. G.: Rank correlation methods, 2nd ed., Hafner Publishing Co., Oxford, England, vii, 196 pp., 1955.

Lamon, L., von Waldow, H., MacLeod, M., Scheringer, M., Marcomini, A., and Hungerbuhler, K.: Modeling the global levels and distribution of polychlorinated biphenyls in air under a climate change scenario, Environ. Sci. Technol., 43, 5818-5824, 2009.

Lenton, T. M.: Early warning of climate tipping points, Nature Clim. Change, 1, 201-209, 2011.

Le Treut, H., Somerville, R., Cubasch, U., Ding, Y., Mauritzen, C., Mokssit, A., Peterson, T., and Prather, M.: Historical Overview of Climate Change, in: Climate Change 2007: The Physical 
Science Basis, Contribution of Working Group I to the Fourth Assessment Report of the Intergovernmental Panel on Climate Change, edited by: Solomon, S., Qin, D., Manning, M., Chen, Z., Marquis, M., Averyt, K. B., Tignor, M., and Miller, H. L., Cambridge University Press, Cambridge, United Kingdom and New York, NY, USA, 2007.

Li, N., Wania, F., Duan, Y. L., and Daly, G. L.: A Comprehensive and critical compilation, evaluation, and selection of physical chemical property data for selected polychlorinated biphenyls, J. Phys. Chem. Ref. Data, 32, 1545-1590, 2003.

Li, Y. F., Scholdz, M. T., and van Heyst, B. J.: Global gridded emission inventory of $\alpha$-hexachlorocyclohexane, J. Geophys. Res., 105, 6621-6632, 2000.

Li, Y. F., Macdonald, R. W., Jantunen, L. M. M., Harner, T., Bidleman, T. F., and Strachan, W. M. J.: The transport of $\beta$ hexachlorocyclohexane to the western Arctic Ocean: a contrast to $\alpha$-HCH, Sci. Total Environ., 291, 229-246, 2002.

Li, Z.: Relative influences of uncertainty in physical-chemical property data and variability in climate parameters in determining the fate of PCBs. Master thesis, Umeå University, Faculty of Science and Technology, available at: http://umu.diva-portal.org/smash/ get/diva2:535806/FULLTEXT01.pdf (28 March 2015), 2012.

Livina, V. N. and Lenton, T. M.: A recent tipping point in the Arctic sea-ice cover: abrupt and persistent increase in the seasonal cycle since 2007, The Cryosphere, 7, 275-286, doi:10.5194/tc-7-2752013, 2013.

Ma, J. and Cao, Z.: Quantifying the perturbations of persistent organic pollutants induced by climate change, Environ. Sci. Technol., 44, 8567-8573, 2010.

Ma, J. and Hung, H.: Reply to "Arctic contaminants and climate change" Nature Clim. Change, 2, 829-830, 2012.

$\mathrm{Ma}$, J. and Li, Y.: Interannual variation of persistent organic pollutants over the Great Lakes induced by tropical Pacific sea surface temperature anomalies, J. Geophys. Res., 111, D04302, doi:10.1029/2005JD006014 2006.

Ma, J., Hung, H., and Blanchard, P. B.: How do climate fluctuations affect persistent organic pollutant distribution in North America? Evidence from a decade of air monitoring, Environ. Sci. Technol., 38, 2538-2543, 2004a.

Ma, J., Cao, Z., and Hung, H.: North Atlantic Oscillation signatures in the atmospheric concentrations of persistent organic pollutants: An analysis using Integrated Atmospheric Deposition Network - Great Lakes monitoring data, J. Geophys. Res.-Atmos, 109, D12305, doi:10.1029/2003JD004435 2004b.

Ma, J., Hung, H., Tian, C., and Kallenborn, R.: Revolatilization of persistent organic pollutants in the Arctic induced by climate change, Nature Clim. Change, 1, 256-260, 2011.

Macdonald, R., Harner, T., and Fyfe, J.: Recent climate change in the Arctic and its impact on contaminant pathways and interpretation of temporal trend data, Sci. Total Environ., 342, 5-86, 2005.

MacLeod, M., Riley, W. J., and Mckone, T. E.: Assessing the influence of climate variability on atmospheric concentrations of Polychlorinated Biphenyls using a Global-Scale Mass Balance Model (BETR-Global), Environ. Sci. Technol., 39, 6749-6756, 2005.

Mann, H. B.: Nonparametric tests against trend, Econometrica, 13, 245-259, 1945.
Meijer, S. N., Ockenden, W. A., Sweetman. A., Breivik, K., Grimalt, J. O., and Jones, K. C.: Global distribution and budget of PCBs and $\mathrm{HCB}$ in background surface soils: Implications for sources and environmental processes, Environ. Sci. Technol., 37, 667672, 2003.

Meyer, T. and Wania, F.: Organic contaminant amplification during snowmelt, Water Res., 42, 1847-1865, 2008.

Moraes, J. M., Pellegrino, H. Q., Ballester, M. V., Martinelli, L. A., Victoria, R., and Krusche, A. V.: Trends in hydrological parameters of a southern Brazilian watershed and its relation to human induced changes, Water Resour. Manag., 12, 295-311, 1998.

Pućko, M., Stern, G. A., MacDonald, R., and Barner, D.: $\alpha$ - and $\gamma$-Hexachlorocyclohexane measurements in the brine fraction of sea ice in the Canadian High Arctic using a sump-hole technique, Environ. Sci. Technol., 44, 9258-9264, 2010.

Shen, L. and Wania, F.: Compilation, evaluation, and selection of physical-chemical property data for organochlorine pesticides, J. Chem. Eng. Data, 50, 742-768, 2005.

Steele, M., Ermold, W., and Zhang, J.: Arctic Ocean surface warming trends over the past 100 years, Geophys. Res. Lett., 35, L0261, doi:10.1029/2007GL0316512008.

Stocker, J., Scheringer, M., Wegmann, F., and Hungerbuhler, K.: Modeling the effect of snow and ice on the global environmental fate and long-range transport potential of semivolatile organic compounds, Environ. Sci. Technol., 41, 6192-6198, 2007.

United Nations Environmental Programme (UNEP), Climate Change and POPs; Predicting the Impacts, Report of the UNEP/AMAP expert group, p. 65 , available at http://www.amap.no/documents/doc/ climate-change-and-pops-predicting-the-impacts/753 (28 March 2015), 2010.

Wang, X., Gong, P., Zhang, Q., and Yao, T.: Impact of climate fluctuations on deposition of DDT and Hexachlorocyclohexane in mountain glaciers: Evidence from ice core records, Environ. Pollut., 158, 375-380, 2010.

Wania, F. and Mackay, D.: Global chemical fate of a hexachlorocyclohexane, 2. Use of a global distribution model for mass balancing, source apportionment, and trend prediction, Environ. Toxicol. Chem., 18, 1400-1407, 1999.

Wania, F., Mackay, D., Li, Y. F., Bidleman, T. F., and Strand, A.: Global chemical fate of alpha-hexachlorocyclohexane, 1. Evaluation of a global distribution model, Environ. Toxicol. Chem., 18, 1390-1399, 1999.

Wöhrnschimmel, H., MacLeod, M., and Hungerbühler, K.: Emissions, fate and transport of persistent organic pollutants to the Arctic in a changing global climate, Environ. Sci. Technol., 47, 2323-2330, 2013.

Wong, F., Jantunen, L. M., Pućko, M., Papakyriakou, T., Stern, G. A., and Bidleman, T. F.: Air-water exchange of anthropogenic and natural organohalogens on International Polar Year (IPY) expeditions in the Canadian Arctic, Environ. Sci. Technol., 45, 876-881, 2010.

Yamamoto, R. T., Iwashima, T., and Sanga, N. K.: Climatic change: a hypothesis in climate diagnosis, J. Meteorol. Soc. Jpn., 63, 1157-1160, 1985.

Zhang, Y., Guan, D., Jin, C., Wang, A., Wu, J., and Yuan, F.: Analysis of impacts of climate variability and human activity on streamflow for a river basin in Northeast China, J. Hydrol., 410, 239-247, 2011. 